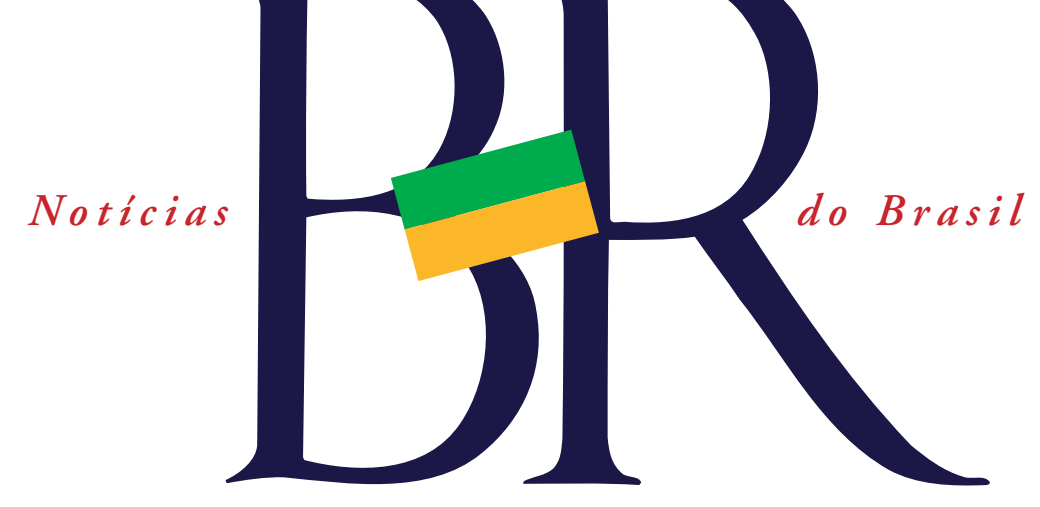

HISTÓRIA

\section{SBPC : 70 anos trabalhando pelo progresso para a ciência brasileira}

\begin{abstract}
A Segunda Guerra Mundial tinha terminado e, cada vez mais, se tornava evidente a necessidade de incentivar a ciência para promover o desenvolvimento social e econômico. No Brasil, um grupo de cientistas discutia os caminhos da ciência. Os principais articuladores eram Mauricio
\end{abstract} Rocha e Silva (Faculdade de Medicina - UFRJ), Paulo Sawaya (Departamento de Fisiologia - USP) e José Reis (Instituto Biológico de São Paulo - IB), mas também outros envolvido como José Ribeiro do Vale (Instituto Butantan), Luiz Gastão Mange Rosenfeld (Faculdade de Ciências Médicas da Santa Casa de São Paulo) e Francisco João Maffei (Instituto de Pesquisas Tecnológicas - USP). Esse grupo decidiu criar, em 8 de julho de 1948, a Sociedade Brasileira para o Progresso da Ciência (SBPC).Ela surge inspirada em instituições como a British Science Association (BSA), que quando foi criada, em 1831, se chamava British Association for the Advancement of Science, e a American Association for the Advancement of Science (AAAS), que surgiu em 1848.

Hoje, não é possível pensar a ciência brasileira sem a SBPC. Seus 70 anos de história foram marcados por uma constante luta pelo desenvolvimento científico e social brasileiro. Criada em um momento em que a produção de ciência no Brasil era muito pequena - na época havia pouquíssimas instituiçóes de pesquisa e as universidades ainda não tinham a tradição de fazer pesquisa - ela contribuiu com o processo de institucionalização da ciência brasileira. Além disso, atuou ativamente em defesa dos direitos humanos, da cidadania, da educação e da democracia. "A criação da SBPC foi um marco na história do país. Ela surge no pós-guerra, quando os países começam a perceber que a ciência era fundamental para seu desenvolvimento social e econômico. E surge para defender o desenvolvimento científico no Brasil, colaborando de modo decisivo para a expansão da ciência no país”, destaca Ildeu de Castro Moreira, atual presidente da SBPC.

Nos primeiros anos de existência, a SBPC trabalhou para o reconhecimento e a institucionalização da ciência no país. A Sociedade participou ativamente da criação da Coordenação de Aperfeiçoamento de Pessoal de Nível Superior (Capes) e do Conselho Nacional de Desenvolvimento Científico e Tecnológico (CNPq), em 1951. Também teve papel fundamental no estabelecimento do Ministério da Ciência, Tecnologia e Inovação, em 1985. Ao longo de sete décadas de atuação também inspirou e apoiou a criação e consolidação de muitas outras sociedades científicas. "No final da década de 1940, já existiam algumas sociedades científicas no Brasil, mas cada uma estava preocupada com a 'sua ciência'. Quando a SBPC é fundada, em 1948, ela conclama todas as áreas do conhecimento a buscarem juntas a expansão e a valorização da ciência nacional. Desta forma, seu diferencial logo no princípio é esse desejo de agregar todas as áreas e os saberes em prol desse desenvolvimento científico", destaca Helena Nader, professora da Universidade Federal de São Paulo (Unifesp) e presidente de honra da SBPC.

Hoje, a SBPC possui cerca de 140 sociedades associadas nas áreas de biológicas, exatas, tecnológicas e humanas e mais de seis mil sócios ativos, entre pesquisadores, docentes, estudantes e cidadãos brasileiros interessados em ciência e tecnologia. Desta forma, ela une diferentes áreas do conhecimento, articulando visões distintas e estabelecendo um diálogo para o avanço da produção do conhecimento nacional.

EDUCAÇÃo Mas não seria possível investir em ciência sem antes pensar na educação científica. "A educação está na base de tudo. Você não vai 
ter ciência de ponta ou inovação sem educação, assim como não vai ter desenvolvimento social, nem mesmo cidadania, sem educação", alerta Nader. De acordo com ela, todos esses processos estão interligados e dependem primeiramente de uma educação de qualidade. "Tudo começa com a educação. Esse é nosso principal desafio hoje. Eé um desafio em todos os níveis, desde a pré-escola, do ensino fundamental até o nível universitário. E também se reflete em todos os aspectos da sociedade, não apenas na ciência, mas também na economia e na saúde". A educação sempre foi uma das bandeiras da SBPC. Por isso, a Sociedade tem diversos projetos de educação científica, como a SBPC Educação, que tem como foco os educadores do ensino fundamental, médio e técnico; a SBPC Vai à Escola, que visa estimular a interação entre cientistas e estudantes dos níveis fundamental e médio através de palestras e atividades nas escolas; e a SBPC Jovem, voltada aos estudantes do ensino básico e realizada durante a reunião anual com o objetivo de promover o contato dos jovens com a pesquisa científica e despertar seu interesse pela ciência, tecnologia e inovação. "A perspectiva educacional sempre esteve presente na história da SBPC. Durante as reuniōes anuais, a presença de crianças e jovens, com participação ativa em diferentes atividades, revela o interesse pela ciência e o papel da entidade na formação do

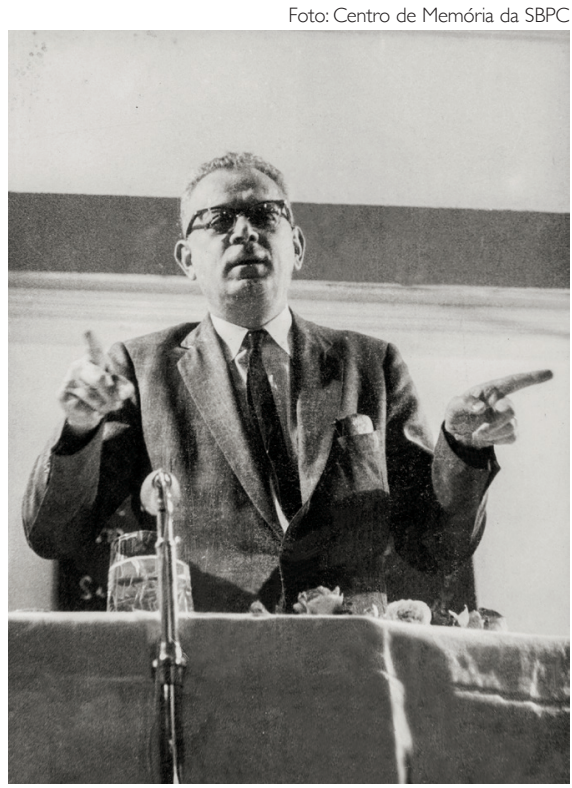

José Reis, um dos idealizadores da SBPC

conhecimento em geral e científico em particular", destaca Graça Caldas, jornalista e pesquisadora do Laboratório de Estudos Avançados em Jornalismo (Labjor) da Unicamp.

DIVULGAÇÃO CIENTíFICA Para envolver toda a sociedade no debate científico, a SBPC realiza reuniōes anuais desde 1949. Nesses eventos, que reúnem cerca de 15 mil pessoas a cada edição, são debatidos temas da ciência, de maneira interdisciplinar, agregando pesquisadores de todo o país. Também são promovidos minicursos, conferências, palestras, encontros, atividades de exposição dos museus de ciência. "Um dos princípios que norteiam a SBPC é a comunicação da ciência - tanto no sentido estrito, ou seja, en- tre a comunidade científica, como no sentido mais amplo, para a sociedade. Assim visa, entre outras coisas, motivar nos jovens e estudantes o interesse pela ciência e pela educação científica de forma geral, e também o engajamento de toda a sociedade no debate dos assuntos da ciência", destaca Carlos Vogt, coordenador do Labjor. Foi a partir dessa visão que, em 1949, um ano depois de sua fundação, a sociedade lançou a revista Ciência \& Cultura, editada até hoje. Em 1982, começou a ser publicada a revista de divulgação científica, Ciência Hoje, que também era vendida nas bancas de jornal. Tal iniciativa surgiu na SBPC Regional do Rio de Janeiro. Em 1986, surgiu a Ciência Hoje das Crianças que teve um impacto muito grande na escola pública. Durante cerca de 25 anos a revista foi enviada a todas as escolas públicas do país pelo Ministério da Educação. Essas publicações, a partir de 2001, passaram a ser de responsabilidade do Instituto Ciência Hoje e, desde 2008, estão disponíveis apenas no formato eletrônico. Em meados de 1985, foi lançado o Jornal da Ciência, que também segue sendo editado atualmente pela SBPC, em versão eletrônica e que inclui o boletim diário JCNotícias. "Os veículos de divulgação científica são essenciais para a formação de uma cultura científica qualificada e competente. Além disso, permitem estabelecer o necessário diálogo da 
ciência e de seus representantes com os diferentes setores da sociedade. A SBPC tem contribuído para a disseminação da CT\&I seja por meio de seus próprios veículos, seja por meio de debates sobre temas contemporâneos que promovem continuamente a ciência nacional", afirma Caldas.

PARA ALÉM DA CIÊNCIA Ao longo de sua história, a SBPC cumpriu, também, um papel fundamental em questóes políticas e sociais. Foi um marco de resistência durante os 21 anos de governo militar (1964-1985), manifestando-se contra perseguições a professores, pesquisadores e estudantes e contra interferências nos sistemas educacional e científico. "Durante a ditadura militar brasileira, a SBPC foi o ambiente de resistência pelos direitos humanos e políticos, uma das poucas entidades a ter voz em meio ao autoritarismo vigente. E é exatamente por ser um espaço democrático e plural de circulação de conhecimento que conquistou credibilidade e respeito da sociedade em geral, contribuindo, assim, para a construção de uma cidadania ativa e participativa", aponta Caldas.

Iniciativas recentes da SBPC também mostram seu envolvimento com questôes que extrapolam o âmbito da ciência, como a participação nas discussões sobre o novo código florestal, exploração da Amazônia, regulamentação de organismos geneticamente modificados e de células-tronco.
A Sociedade participa ativamente de debates sobre questóes de políticas científicas e de educação no Brasil, tendo assento permanente no Conselho Nacional de Ciência e Tecnologia (CCT), órgão consultivo do governo federal para definição das políticas e ações prioritárias no campo da C\&T. Também possui representantes oficiais em mais de 20 conselhos e comissões governamentais. "O diálogo entre cientistas e o governo tem que ser cada vez maior. Eu acredito nessa aproximação, nesse trabalho conjunto. É um trabalho contínuo, mas que deve ser feito, porque através desse debate pode-se construir muita coisa boa para o povo brasileiro", enfatiza Nader.

Como parte das comemorações dos 70 anos, no primeiro semestre deste ano, a SBPC coordenou um ciclo de oito seminários temáticos "Políticas públicas para o Brasil que queremos". O objetivo foi discutir políticas públicas nas áreas de ciência, tecnologia e inovação, educação básica e superior e pós-graduação, democratização da comunicação, direitos humanos, desenvolvimento sustentável, Amazônia e saúde pública. Ao final de cada encontro foi elaborado um documento com diretrizes e propostas gerais para essas políticas que serão encaminhados aos candidatos, tanto ao legislativo quanto ao executivo, da próxima eleição. "A SBPC é uma sociedade comprometida com a formulação de boas políticas públicas que visem não apenas o desenvolvimento científico e tecnológico do país, mas que atendam às necessidades e aos interesses maiores da sociedade brasileira; e ainda luta pela qualidade e universalidade da educação em todos os níveis e pelo amplo acesso público à divulgação da ciência e da tecnologia. Esse compromisso faz com que ela tenha uma militância muito grande junto ao governo buscando o cumprimento desses objetivos", enfatiza Vogt.

Nos últimos anos, a ciência brasileira avançou muito. As pesquisas em agropecuária e aeronáutica estão entre as melhores do mundo e nas últimas duas décadas a produção científica cresceu de forma expressiva (o Brasil ocupa o $13^{\circ}$ lugar na produção científica mundial). No entanto, tem que enfrentar muitos desafios, como o decréscimo acentuado de recursos nos últimos anos e problemas na educação básica. A SBPC ainda tem muito trabalho pela frente. "Nós queremos um país democrático, que respeite os direitos humanos e defenda a liberdade de pesquisa, de expressão, de comunicação. A ciência é necessária o tempo todo. O Brasil precisa dela para um desenvolvimento sustentável e inteligente, que contribua para a melhoria da qualidade de vida de todos os seus cidadãos. Ciência e tecnologia são essenciais para a soberania de um país", finaliza Moreira. 